\title{
Editor's Introduction to Volume 4, Issue 2
}

Before introducing Volume 4, Issue 2 of the International Journal of Rural Criminology, I have three simple requests for those interested in submitting a manuscript. First, please send the manuscript in word format, and do not, under any circumstances, send it in any kind of pdf format. Second, use only endnotes, and do NOT use footnotes. By endnotes I mean that one should click on the superscript command to indicate an additional comment (give it a number), and then between the end of the manuscript's narrative and the references, enter the words associated with each endnote. Several of the manuscripts in this issue demonstrate how endnotes work, should my humble attempt to describe the process be less than clear. Third, conform to APA style on reference format and citations within the narrative itself. Either refer to https://owl.purdue.edu/owl/research_and_citation/apa_style/apa_style_introduction.html,or simply sample several of the manuscripts in this issue and follow what they do.

Articles for this issue of the International Journal of Rural Criminology come from research in five different countries, and one who perspective is more world-wide. Beyond geographic diversity, there is also subject matter, methodological and theoretical diversity.

The lead-off article, by Artur Pytlarz and Matt Bowden, is from rural Ireland. It is both substantive in its intent - security concerns in a changing rural community located about an hour's drive from Dublin - and, methodological in its focus through the use of "crime talk" to gather and analyze perceptions of residents' views about crime and safety. The authors devote the final pages of their narrative to a "Postscript", describing "crime talk" and how they used it.

Following upon the methodological considerations of Pytlarz and Bowden, the authors of the second article - Neubacher, Faße, Bögelein, and Grote - noted that "most findings are concerned with the developed, especially the Western, world. There are many reasons for this: on the one hand the strong position of Anglo-American criminology...and, on the other hand, the various difficulties of conducting field research in developing countries." (p. 174). The authors used a victimization survey, similar to the International Crime Victims Survey, but supplemented by additional questions that account for the rural and agricultural base of their respondents, to examine both the level of crime and how these rural Tanzanians perceive their security. Like the first article, Neubacher, Faße, Bögelein, and Grote conclude with a discussion of the methodological challenges of conducting rural-based criminological research.

Ulrich-Schad, Fedder and Yingling, the authors of the third article in volume 4, issue 2 of IJRC, have written an article surprisingly similar to the work from rural Tanzania, and for that matter, rural Ireland. All share a similar focus on social change and its impacts on perceptions of safety and security of people living in rural communities. For Ulrich-Schad, Fedder and Yingling, the focus is on the Balken Region of Montana and North Dakota in the northern U.S. 
where rural places are experiencing a large influx of energy workers. One of their primary conclusions can be found on page (p. 205). In regard to perceptions of crime problems, the authors observed: "the lower percentages we find for more serious crimes being caused by...oil and gas development are due to fewer people having evidence of the crimes being a problem in their community, rather than fewer people believing oil and gas development have at least partially caused it."

The fourth article, by Zekiwos-Gichamo, Karltun, Tolera, and Chiwona-Karltun, is a follow-up from an earlier published article by three of the same authors (plus two others) in IJRC (Volume 3, Issue 2), which itself a special issue on agricultural crime. This article is a focus on the obstacles of re-introducing faba bean production in an area of Ethiopia where production was substantially reduced by farmers due to theft. Reflecting also the impact of change, the authors cite previous scholarly work on food-sharing, which in essence means a certain amount of tolerance for the theft of faba beans if the cost of protecting the beans from theft is higher than not sharing at all. Times have changed, and faba bean theft is less something committed by a hungry person who needs a bit of food, and more about theft for economic motives. Obstacles to the re-introduction of faba beans has important environmental (as well as economic and sociological consequences) because of their nitrogen-fixing qualities, requiring less fertilizers and other chemicals (which can be expensive) that potentially pollute water courses and water wells.

The previous articles in this issue used a variety of primary data collection techniques, including surveys, personal interviews, and focus groups. In this article, Osbourne, Swartz, and Stover describe a very innovative approach to the study of agricultural theft in the United States by tapping into a secondary dataset, called by its abbreviation - NIBRS (National Incident-Based Reporting System). The authors offer an excellent journey through the relative advantages of using NIBRS data for an analysis of agricultural crime in terms of estimating prevalence and trends, examining incident-level data, assessing types of thefts committed against agricultural operations, and applying/testing criminological theory to the theft prevalence. Table 2 (p. 246) is particularly interesting, because it documents the economic seriousness of agricultural crime. The average value of an incident of theft was $\$ 3,744$ (USD) for equipment, $\$ 7,182$ for livestock, and $\$ 20,185$ for crops.

The authors of the sixth article in this issue of the International Journal of Rural Criminology are Joseph Rukus and Veena Kulkarni. Like the previous article, Rukus and Kulkarni focus mostly on methodology, specifically, the complications and challenges of achieving IRB (Institutional Review Board) approval for research on human subjects. In this case, the subjects are inmates in rural jails. Anyone who has ever dealt with the IRB approval process and claim it was both easy and enjoyable should themselves consult psychiatric help because they are likely suffering from an extreme case of the Pollyanna syndrome $:-$. In their 
narrative on the obstacles to achieve IRB approval, Rukus and Kulkarni offer two basic kinds of advice. First, be proactive in communicating with one's IRB Board by consulting with them on various issues before the formal submission of a proposal. Second, be patient - constantly.

With Hollis and Hankhouse, we move from research methods to theory. Specifically, this $7^{\text {th }}$ article in the current issue considers and applies the concept of guardianship from Routine Activities Theory to a discussion of its relevance for understanding patterns of crime within rural placers. Breaking down guardians into three kinds - handlers, managers and target guardians Hollis and Hankhouse turn their attention to the rural context of routine activity patterns, land use, traffic, and the availability of targets. Their article shows not only the potential of applying a well-established criminological theory to the study of rural crime, but shows how rural contexts demands of criminological theories more generally a greater appreciation for distinctions from urban contexts.

Never, to the best of my knowledge, has an article on rural crime in Saudi Arabia been published, but that is no longer true with this issue of the International Journal of Rural Criminology. Mofza Algahtany, Lalit Kumar and Elaine Barclay are the authors who changed it. They present an analysis of crime variations across the province of Jizan in southern Saudi Arabia, based on both population density and road conditions. Their results are a reminder that rural context can turn what are believed to be established research findings upside down. In this analysis, urban localities may have exhibited higher rates of offences for alcohol, assault, theft, and sexual crimes. However, certain crimes were more prevalent in the regions with low population density and unpaved roads - namely, kidnapping, robbery, murder, and drugs.

The final article in this issue is by Walter DeKeseredy, on the current state of sociological knowledge about violence against rural women. He calls for improved theoretical perspectives and more ethnographic research on violence against women in rural communities beyond the U.S. and other developed societies, a much greater focus on male offenders, and a greater consideration intimate partner violence amongst members of the LGBTQ community who live beyond city limits. He concludes with an observation that can be applied to all criminological and criminal justice issues associated with the study of rural crime. To quote: This review article is a story about sociological ways of knowing about rural violence against women and as it ends, it is apparent in some ways, the story is just beginning. Violence against women in rural places as a social issue is constantly evolving and never-ending" (page 323).

Altogether, these 9 articles form nearly 200 pages of new contributions to the development of rural criminology and the study of rural crime. Please download, read, enjoy, and learn! 